\title{
THE PROGNOSIS, MANAGEMENT AND DISPOSAL OF THE SERVICE PATIENT
}

\author{
LT COL I C CRAWFORD, MB, FRCP, RAMC
}

Primary prevention is considered briefly. The Army has no programme of planned screening; perhaps it should. There is much to be said for the regular measurement of blood pressure, particularly amongst older people for whom also more should be done to stop smoking. Beta-blockers have changed the treatment of hypertension and there is a certain amount of soft evidence that they prevent coronary heart disease. Obesity and physical fitness are battles which you win once the patient has had his first myocardial infarct, not before.

The problem for the Service physician is often that of a man aged 40 , a thrusting major or warrant officer about to be commissioned, who has had a myocardial infarct. It is uncomplicated and he makes a complete recovery. A few years ago we were being counselled in such cases to proceed to coronary arteriography at about six weeks. Logistic problems precluded this course of action and the present plan is for an exercise test at about three months using a bicycle (now treadmill) and a 12-lead electro-cardiogram during various stages of exercise. Towards the end of the exercise a thallium scan is undertaken to determine myocardial perfusion. A poor result or marked changes in the ECG during exercise are then reasons for coronary arteriography and for deciding if there might perhaps be benefit from cardiac surgery.

The surgical procedure at present advocated is the coronary artery bypass operation. Such operations have been successfully conducted for at least the past six years in this country and it is now possible to assess the results. The myocardium revascularizes well and the patient gets relief from his symptoms. Unfortunately there is no evidence that the operation prevents premature death or that it prevents further cardiovascular incidents. There is no doubt that it does improve the quality of life. It is remarkably effective at relieving symptoms.

Medical treatment is disappointing. Present practice is to administer no medication except possibly beta-blockers. As far as categorization and assessment are concerned the usual recommendation is Pulheems category P7 for one year and P3 thereafter but never P2 unless the case is a quite exceptional one.

\section{CORONARY HEART DISEASE IN THE CIVIL SERVICE}

\section{DR A M SEMMENCE, MD, MSc, FRCGP}

Applying England and Wales' age specific death rates to the 260,000 male and 220,000 female non-industrial civil servants in post on 1 January 1978, 1903 deaths from all causes would have been expected in the men during 1978, with over a third of them due to ischaemic heart disease (Table VIII). One hundred and twelve women could also have been expected to die of ischaemic heart disease in 1978. There are wide grade differences in deaths from coronary 